\title{
Nghiên cứu giải pháp xử lý nền bằng trụ đất xi măng cho công trình bể chứa xăng dầu ở tỉnh Tiền Giang
}

\author{
Nguyễn Ngọc Thắng ${ }^{1}$, Thiệu Ngọc Hồ ${ }^{2 *}$
}

${ }^{1}$ Khoa Kỹ thuật công nghệ, Trường Đại học Tiền Giang

${ }^{2}$ Khoa Kỹ thuật công nghệ, Trường Đại học Kinh tế Công nghiệp Long An

\begin{tabular}{l} 
TỪ KHOÁ \\
\hline Bể chứa \\
Trụ đất xi măng \\
Plaxis 2D \\
Gia cố \\
Đất yếu
\end{tabular}

TÓM TẮT

Muốn xây dựng công trình trên vùng đất yếu cần phải có giải pháp xử lý nhằm tăng sức chịu tải và giảm khả năng biến dạng. Chính vì vậy việc tìm ra giải pháp gia cố nền vừa hiệu quả vừa tiết kiệm chi phí, giảm gây ô nhiễm môi trường rất được quan tâm trong thiết kế xây dựng hiện nay. Giải pháp gia cố nền đất sử dụng công nghệ trụ đất xi măng đáp ứng được hầu hết các yêu cầu về mặt kinh tế và kỹ thuật. Trong nghiên cứu này, sử dụng mô hình số (Plaxis 2D) để mô phỏng sự phân bố ứng suất, biến dạng trong nền đất yếu vào công trình bể chứa xăng dầu được gia cố nền bằng trụ đất xi măng tại phường 6 , thành phố Mỹ Tho, tỉnh Tiền Giang.

\section{KEYWORDS}

\section{Tank}

Cement deep mixing columns

Plaxis 2D

Reinforce

Soft soil

\begin{abstract}
To build works on soft soil, it is necessary to have treatment solutions to increase the load capacity and reduce the ability of deformation, so find a solution to reinforce the foundation that is both effective and cost-effective, reducing environmental pollution is of great interest in building design today. The solution to reinforce the ground using cement ground technology meets most of the economic and technical requirements. In this study, using a numerical model (Plaxis 2D) to simulate the distribution of stress and deformation in soft ground into petroleum storage tanks by cement deep mixing columns in ward 6, My Tho city, Tien Giang province.
\end{abstract}

\section{Giới thiệu}

Bể chứa xăng dầu (bể chứa trụ đứng) thường có đường kính lớn ( $\mathrm{D}=20 ; 30 ; 40 ; 50 \mathrm{~m}$ ), chiều cao không lớn $(\mathrm{H}=10,12 \mathrm{~m}$ ) và xăng dầu chứa trong đó có trọng lượng thể tích nhỏ (thường nhỏ hơn 0,95 Tấn/ $\mathrm{m}^{3}$ ) nên áp lực lên nền không lớn, nhưng do đường kính bể lớn nên ứng suất gây lún phát triển khá sâu, vùng chịu nén lún lớn. Vì vậy, tùy theo điều kiện địa chất của từng vùng và chiều dày của lớp đất yếu mà áp dụng thích hợp các phương pháp xử lý nền.

Các phương pháp xử lý nền đất yếu trên đều có tác dụng tăng tính ổn định và giảm độ lún của nền đất, được áp dụng trong từng trường hợp xử lý cụ thể. Tuy nhiên, khi đất yếu khó thấm nước như sét mềm yếu, bùn sét,...(đặc trưng đất ở đồng bằng sông Cửu Long nói chung, tỉnh Tiền Giang nói riêng) thì trong những trường hợp nhất định nào đó, phương pháp xử lý nền đất yếu bằng trụ đất xi măng được cho là có hiệu quả kinh tế kỹ thuật hơn các phương pháp xử lý nền đất yếu khác, vì hệ số thấm của đất sét gia cố có thể tăng từ 400 đến 800 lần so với đất sét chưa được gia cố. Với đặc tính về loại công trình, đặc điểm về vị trí đặt công trình (khu vực ven sông, ven biển), để gia cố nền đất yếu dưới công trình bể chứa, tác giả cho rằng sử dụng phương pháp xử lý nền đất yếu bằng trụ đất xi măng hoàn toàn phù hợp và khả thi.

\section{Phân tích và tính toán nền dưới công trình đắp cao}

2.1. Điều kiện địa chất tại TP. Mỹ Tho - tỉnh Tiền Giang

Để có số liệu về các tính chất của đất tự nhiên, một hố khoan 30 $\mathrm{m}$ được khoan khảo sát tại tp. Mỹ Tho - tỉnh Tiền Giang. Kết quả của các thí nghiệm xác định các chỉ tiêu cơ lý của các lớp đất được thể hiện trong Bảng 1.

Bảng 1.

Đặc trưng chỉ tiêu cơ lý của các lớp đất.

\begin{tabular}{|l|c|c|c|c|c|}
\hline \multicolumn{1}{|c|}{ Chỉ tiêu cơ lý } & Lớp 1 & Lớp 2 & Lớp 3 & Lớp 4 & Lớp 5 \\
\hline Độ ẩm tự nhiên, $\mathrm{W}(\%)$ & 30,1 & 24,0 & 27,7 & 24,4 & 24,5 \\
\hline $\begin{array}{l}\text { Dung trọng ướt, } \\
\gamma_{\mathrm{w}}\left(\mathrm{kN} / \mathrm{m}^{3}\right)\end{array}$ & 18,67 & 19,29 & 18,98 & 19,19 & 19,61 \\
\hline $\begin{array}{l}\text { Dung trọng khô, } \\
\gamma_{\mathrm{d}}\left(\mathrm{kN} / \mathrm{m}^{3}\right)\end{array}$ & 14,36 & 15,55 & 14,87 & 15,43 & 15,76 \\
\hline
\end{tabular}

"Tác giả liên hệ: thieungocho@gmail.com 


\begin{tabular}{|l|c|c|c|c|c|}
\hline \multicolumn{1}{|c|}{ Chỉ tiêu cơ lý } & Lớp 1 & Lớp 2 & Lớp 3 & Lớp 4 & Lớp 5 \\
\hline $\begin{array}{l}\text { Dung trọng đẩy nồi, } \\
\gamma_{\text {sub }}\left(\mathrm{kN} / \mathrm{m}^{3}\right)\end{array}$ & 9,04 & 9,77 & 9,37 & 9,69 & 9,96 \\
\hline Tỉ trọng, $\mathrm{G}_{\mathrm{s}}$ & 2,701 & 2,688 & 2,703 & 2,690 & 2,716 \\
\hline Độ rỗng, (\%) & 45,8 & 41,0 & 43,9 & 41,5 & 40,9 \\
\hline Hệ số rồng, $\mathrm{e}_{0}$ & 0,849 & 0,696 & 0,785 & 0,711 & 0,692 \\
\hline Độ bảo hòa, (\%) & 96,0 & 92,9 & 95,4 & 92,1 & 96,0 \\
\hline Giới hạn chảy, LL(\%) & 40,6 & 29,6 & 41,9 & 33,9 & 44,0 \\
\hline Giới hạn dẻo, PL(\%) & 19,7 & 17,9 & 21,0 & 18,9 & 21,7 \\
\hline Chỉ số dẻo (\%) & 21,0 & 11,7 & 21,0 & 14,9 & 22,3 \\
\hline Độ sệt, IL(\%) & 0,5 & 0,53 & 0,32 & 0,36 & 0,12 \\
\hline Lựic dính, c(kN/m $\left.{ }^{2}\right)$ & 16,25 & 16,85 & 22,41 & 19,88 & 31,61 \\
\hline Góc ma sát, $\varphi$ & $11^{\circ} 22^{\prime}$ & $14^{\circ} 58^{\prime}$ & $15^{\circ} 29^{\prime}$ & $16^{\circ} 30^{\prime}$ & $16^{\circ} 30^{\prime}$ \\
\hline Hệ số nén lún $\left(\mathrm{m}^{2} / \mathrm{kN}\right)$ & $4,3 \mathrm{E}-04$ & $3,0 \mathrm{E}-04$ & $3,0 \mathrm{E}-04$ & $3,3 \mathrm{E}-04$ & $2,2 \mathrm{E}-04$ \\
\hline $\begin{array}{l}\text { Mô đun biến dạng, } \\
\text { E }\end{array}$ & $1677,3\left(\mathrm{kN} / \mathrm{m}^{2}\right)$ & 3435,8 & 2317,6 & 3206 & 3120,2 \\
\hline
\end{tabular}

Các trường hợp mô phỏng với $\mathrm{L}=12 \mathrm{~m}$.

\begin{tabular}{|c|c|c|c|}
\hline $\begin{array}{c}\text { Các trường hợp } \\
\text { mô phỏng }\end{array}$ & $\begin{array}{l}\text { Chiều } \\
\text { dài } \\
\text { L (m) }\end{array}$ & $\begin{array}{c}\text { Đường } \\
\text { kính } \\
\text { D (m) }\end{array}$ & $\begin{array}{c}\text { Khoảng cách từ } \\
\text { tim giữa các trụ } \\
\text { S (m) }\end{array}$ \\
\hline Trường hợp 1 - B & \multirow{9}{*}{12} & \multirow{3}{*}{0,6} & 0,8 \\
\hline Trường hợp 2 - B & & & 1,0 \\
\hline Trường hợp 3 - B & & & 1,2 \\
\hline Trường hợp 4 - B & & \multirow{3}{*}{0,8} & 1,0 \\
\hline Trường hợp 5 - B & & & 1,2 \\
\hline Trường hợp 6 - B & & & 1,4 \\
\hline Trường hợp 7 - B & & \multirow{3}{*}{1,0} & 1,2 \\
\hline Trường hợp 8 - B & & & 1,4 \\
\hline Trường hợp 9 - B & & & 1,6 \\
\hline
\end{tabular}

Tổng cộng có 18 mô hình được phân tích mô phỏng.

2.3. Mô hình tính toán nền đất yếu được xử lý bằng trụ đất xi măng

2.2.Phương án bố trí trụ đất xi măng

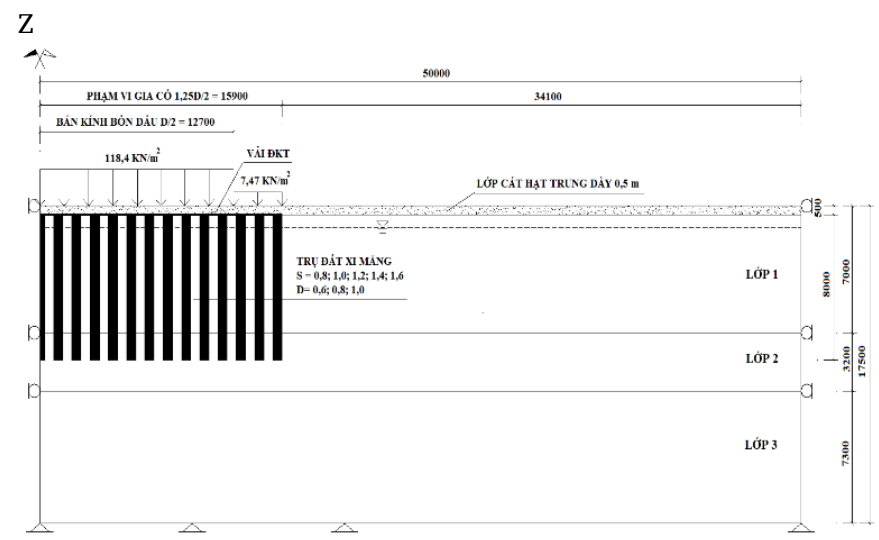

Hình 1. Mặt cắt ngang điển hình xử lý nền đất yếu bằng trụ đất xi măng tương ứng với các trường hợp ở Bảng 1.

Bảng 2.

Các trường hợp mô phỏng với $\mathrm{L}=8 \mathrm{~m}$.

\begin{tabular}{|c|c|c|c|}
\hline $\begin{array}{c}\text { Các trường hợp } \\
\text { mô phỏng }\end{array}$ & $\begin{array}{l}\text { Chiều dài } \\
\text { L (m) }\end{array}$ & $\begin{array}{c}\text { Đường kính } \\
\text { D (m) }\end{array}$ & $\begin{array}{l}\text { Khoảng cách từ } \\
\text { tim giữa các trụ } \\
\text { S (m) }\end{array}$ \\
\hline Trường hợp 1 - A & \multirow{9}{*}{8} & \multirow{3}{*}{0,6} & 0,8 \\
\hline Trường hợp 2 - A & & & 1,0 \\
\hline Trường hợp 3 - A & & & 1,2 \\
\hline Trường hợp 4 - A & & \multirow{3}{*}{0,8} & 1,0 \\
\hline Trường hợp 5 - A & & & 1,2 \\
\hline Trường hợp 6 - A & & & 1,4 \\
\hline Trường hợp 7 - A & & \multirow{3}{*}{1,0} & 1,2 \\
\hline Trường hợp 8 - A & & & 1,4 \\
\hline Trường hợp 9 - A & & & 1,6 \\
\hline
\end{tabular}

Bảng 3.

Các phương án mô phỏng thay đổi chiều dài, khoảng cách trụ và đường kính của trụ đất xi măng, từ các kết quả phân tích, tiến hành lựa chọn phương án hợp lý gia cố nền cho bể chứa xăng dầu, các phương án như sau:

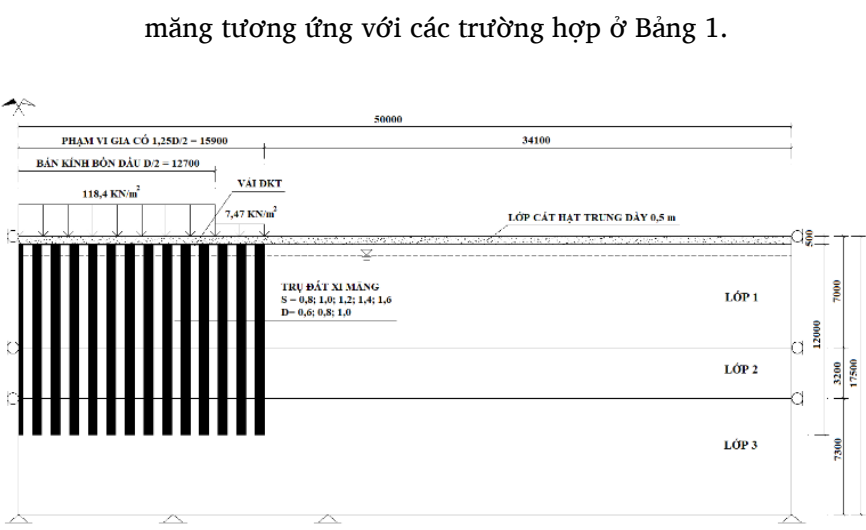

Hình 2. Mặt cắt ngang điển hình xử lý nền đất yếu bằng trụ đất xi măng tương ứng với các trường hợp ở Bảng 2. 
Trụ đất xi măng có đường kính và khoảng cách được bố trí theo các phương án ở Bảng 2 và Bảng 3 . Theo Hình 1 và Hình 2 cho biết nửa nền bể chứa xăng dầu được cải tạo gia cố, khoảng cách theo phương ngang là 50 m; khoảng cách theo phương đứng là 17,5 m; các kích thước giá trị tính toán theo phương ngang phạm vi bể chứa (D/2) rộng $12,7 \mathrm{~m}$ chịu tải phân bố đều $118,4 \mathrm{kN} / \mathrm{m}^{2}$, phạm vi gia cố ngoài bể chứa $(1,25 \mathrm{D} / 2)$ là từ 12,7 đến 15,9 chịu tải phân bố đều $7,47 \mathrm{kN} / \mathrm{m}^{2}$.

Khi phân tích phần tử hữu hạn theo 2 phương có thể sử dụng mô hình biến dạng phẳng hoặc mô hình đối xứng trục. Để mô hình hóa cho các lớp đất có thể dùng phần tử tam giác 6 nút hoặc 15 nút đưa về bài toán phẳng để tính toán. Phần tử hình tam giác 6 nút là phần tử mặc định cho một sự phân tích 2 chiều.

\section{4. Điều kiện biên}

Sử dụng định dạng Standard fixities để khai báo điều kiện biên. Những điều kiện biên này là những quy tắc được phát sinh sau: Những kết cấu theo phương đứng mà tọa độ $\mathrm{x}$ bằng giá trị thấp nhất hoặc cao nhất trong mô hình thu được một tính ngàm ngang $\left(\mathrm{u}_{\mathrm{x}}=0\right)$. Những kết cấu theo phương ngang mà tọa độ $\mathrm{y}$ bằng giá trị thấp nhất hoặc cao nhất trong mô hình thu được một tính ngàm đầy đủ $\left(\mathrm{u}_{\mathrm{x}}=\mathrm{u}_{\mathrm{y}}=0\right)$.

\subsection{Khai báo đặc trưng vật liệu}

Mô hình Mohr - Coulomb được chọn để mô tả các tính chất thực của đất và khả năng ứng dụng tính toán của Version 8.2. Đây là mô hình đàn hồi dẻo lý tưởng gồm 5 tham số cơ bản của đất là mô đun đàn hồi (E), hệ số poisson $(\mu)$, lực dính đơn vị (c), góc ma sát trong ( $\varphi$ ) và góc giãn nở $(\psi)$. Một thuộc tính quan trọng của đất là sự tồn tại của áp lực nước lỗ rỗng. Ảnh hưởng của áp lực nước lỗ rỗng gồm 2 loại quan hệ là: Quan hệ thoát nước (drained behavior) và quan hệ không thoát nước (undrained behavior).

\section{Bảng 4.}

Thông số các lớp đất trong mô hình Plaxis.

\begin{tabular}{|l|c|c|c|c|}
\hline Tham số & $\begin{array}{c}\text { Lớp cát } \\
\text { đầm } \\
\text { chặt }\end{array}$ & Lớp 1 & Lớp 2 & Lớp 3 \\
\hline Mô hình & $\begin{array}{c}\text { Mohr - } \\
\text { Coulomb }\end{array}$ & $\begin{array}{c}\text { Mohr - } \\
\text { Coulomb }\end{array}$ & $\begin{array}{c}\text { Mohr - } \\
\text { Coulomb }\end{array}$ & $\begin{array}{c}\text { Mohr - } \\
\text { Coulomb }\end{array}$ \\
\hline Ứng xử vật liệu & Drained & $\begin{array}{l}\text { Un- } \\
\text { drained }\end{array}$ & Un-drained & Un-drained \\
\hline $\begin{array}{l}\text { Dung trọng tự nhiên, } \\
\gamma_{\text {unsat }}\left(\mathrm{kN} / \mathrm{m}^{3}\right)\end{array}$ & 18,00 & 18,67 & 19,29 & 18,98 \\
\hline
\end{tabular}

\begin{tabular}{|l|l|l|l|l|}
\hline Tham số & $\begin{array}{c}\text { Lớp cát } \\
\text { đầm } \\
\text { chặt }\end{array}$ & \multicolumn{1}{|c|}{ Lớp 1 } & Lớp 2 & Lớp 3 \\
\hline $\begin{array}{l}\text { Dung trọng bão hòa, } \\
\gamma_{\text {sat }}\left(\mathrm{kN} / \mathrm{m}^{3}\right)\end{array}$ & 20,00 & 19,20 & 19,95 & 19,54 \\
\hline $\begin{array}{l}\text { Hệ số thấm phương } \\
\mathrm{x}, \mathrm{k}_{\mathrm{x}}(\mathrm{m} / \text { day })\end{array}$ & $10^{-3}$ & $10^{-6}$ & $10^{-6}$ & $10^{-6}$ \\
\hline $\begin{array}{l}\text { Hệ số thấm phương } \\
\text { y, } \mathrm{k}_{\mathrm{y}}(\mathrm{m} / \text { day })\end{array}$ & $10^{-3}$ & $10^{-6}$ & $10^{-6}$ & $10^{-6}$ \\
\hline $\begin{array}{l}\text { Mô đun đàn hồi, } \\
\left.\text { E(kN/m }{ }^{2}\right)\end{array}$ & 20000 & 1677 & 3436 & 2318 \\
\hline Hệ số Poisson $v(-)$ & 0,330 & 0,333 & 0,305 & 0,333 \\
\hline $\begin{array}{l}\text { Cường độ kháng cắt } \\
\mathrm{c}\left(\mathrm{kN} / \mathrm{m}^{2}\right)\end{array}$ & 10,00 & 16,25 & 16,85 & 22,41 \\
\hline $\begin{array}{l}\text { Góc ma sát trong, } \\
\varphi\left({ }^{\circ}\right)\end{array}$ & $25^{0}$ & $11^{0} 22^{\prime}$ & $14^{0} 58^{\prime}$ & $15^{0} 29^{\prime}$ \\
\hline Góc dãn nở, $\psi\left({ }^{\circ}\right)$ & $0^{0}$ & $0^{0}$ & $0^{0}$ & $0^{0}$ \\
\hline
\end{tabular}

Tính chất của trụ đất xi măng được thí nghiệm từ thí nghiệm xác định $\mathrm{q}_{\mathrm{u}}$ và tham khảo các tài liệu về tính chất của trụ đất xi măng: Trọng lượng riêng theo Kamata \& Akutsu, 1976 cho rằng trọng lượng riêng của đất trộn xi măng tăng từ $3 \%$ đến $15 \%$. Từ các thí nghiệm nén mẫu, module đàn hồi $\mathrm{E} 50=(50 \div 63) \mathrm{q}_{\mathrm{u}}$. Hệ số Poission theo Niina et al., 1977 đề nghị lấy từ 0,15 đến 0,35

Bảng 5. Thông số trụ đất xi măng trong mô hình Plaxis.

\begin{tabular}{|l|l|}
\hline Tham số & Trụ đất xi măng \\
\hline Mô hình & Mohr-Coulomb \\
\hline Ứng xử vật liệu & Un-drained \\
\hline Dung trọng tự nhiên, $\gamma_{\mathrm{unsat}}\left(\mathrm{kN} / \mathrm{m}^{3}\right)$ & 11,15 \\
\hline Dung trọng bão hòa, $\left.\gamma_{\mathrm{sat}} \mathrm{kN} / \mathrm{m}^{3}\right)$ & 18,40 \\
\hline Hệ số thấm phương $\mathrm{x}, \mathrm{k}_{\mathrm{x}}(\mathrm{m} / \mathrm{day})$ & $10^{-7}$ \\
\hline Hệ số thấm phương $\mathrm{y}, \mathrm{k}_{\mathrm{y}}(\mathrm{m} /$ day) & $10^{-7}$ \\
\hline Mô đun đàn hồi, $\mathrm{E}\left(\mathrm{kN} / \mathrm{m}^{2}\right)$ & 100000 \\
\hline Hệ số Poisson $v(-)$ & 0,333 \\
\hline Cường độ kháng cắt, $\mathrm{c}\left(\mathrm{kN} / \mathrm{m}^{2}\right)$ & 175 \\
\hline Góc ma sát trong, $\varphi\left(^{\circ}\right)$ & $30^{0}$ \\
\hline Góc dãn nở, $\psi\left({ }^{\circ}\right)$ & $0^{0}$ \\
\hline
\end{tabular}

Vải địa kỹ thuật được mô phỏng bởi phần tử Geogrid có $\mathrm{EA}=2500$ kN/m.

\subsection{Tính toán}

Mỗi mô hình được phân tích theo các giai đoạn: thi công trụ đất xi măng, thi công Vải địa kỹ thuật, thi công lớp cát đệm, thi công lớp bê tông nhựa và chất tải. Bao gồm: Tính toán dẻo (Plastic Calculate), Phân tích cố kết (Consolidation Analysis) và phân tích an toàn (Giảm 
$\varphi)$ (Safety Analysis).

3. Kết quả mô phỏng và phân tích kết quả

3.1. Trường hơp 3 - A: $D=0,6 \mathrm{~m} ; S=1,2 \mathrm{~m} ; L=8$

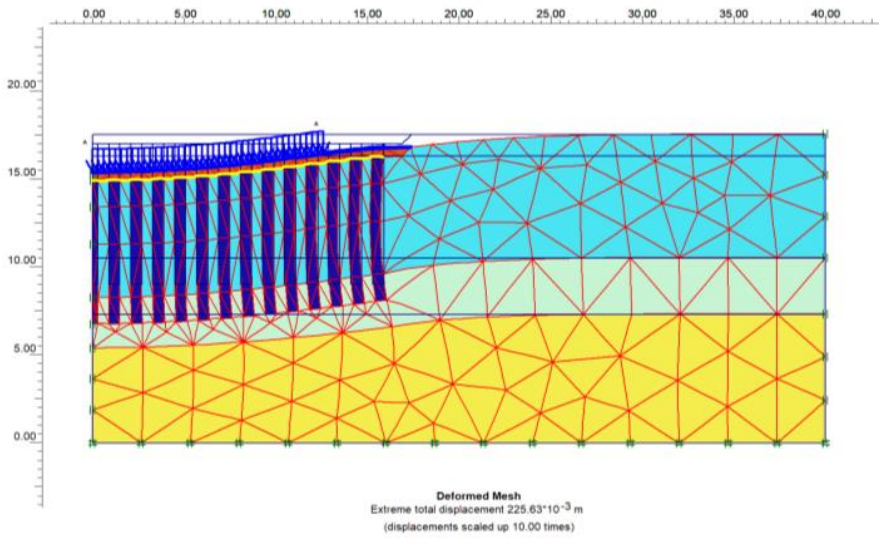

Hình 3. Chuyển vị của nền đất yếu được gia cố.

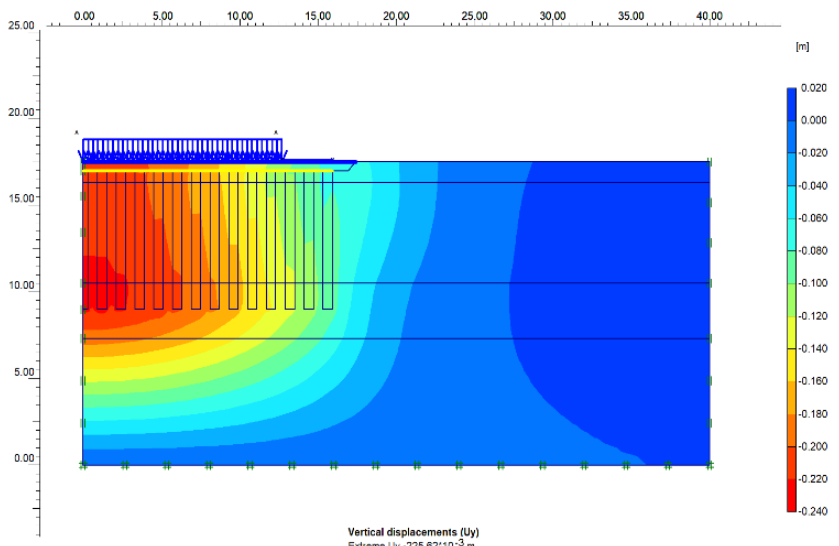

Hình 4. Chuyển vị theo phương đứng của nền đất yếu được gia cố.

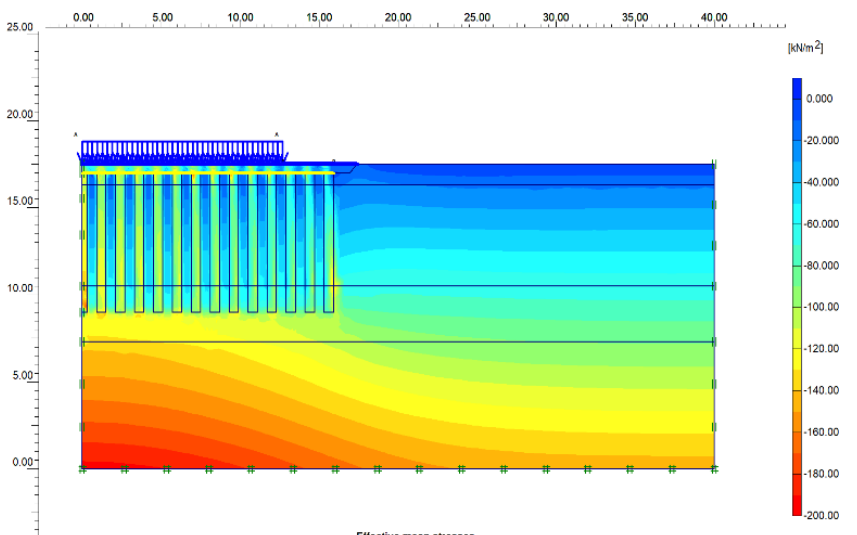

Hình 5. Sự phân bố ứng suất hữu hiệu trong nền đất yếu được gia cố.

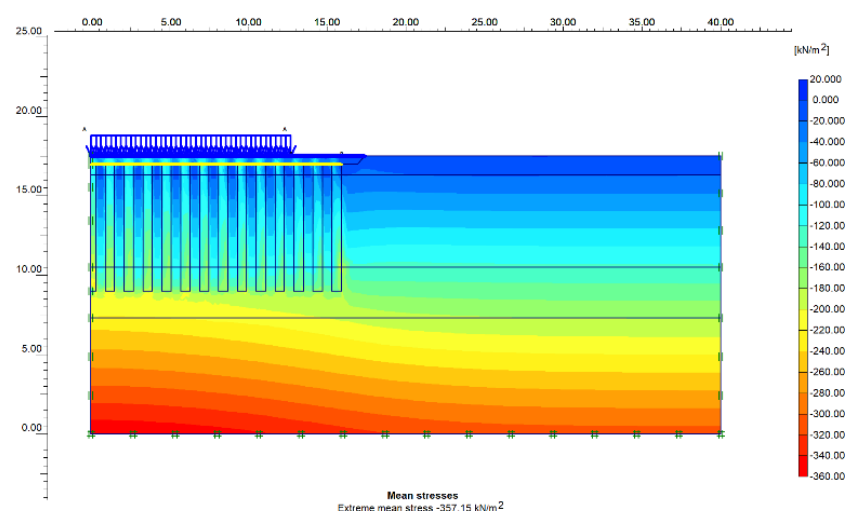

Hình 6. Sự phân bố ứng suất tổng trong nền đất yếu được gia cố.

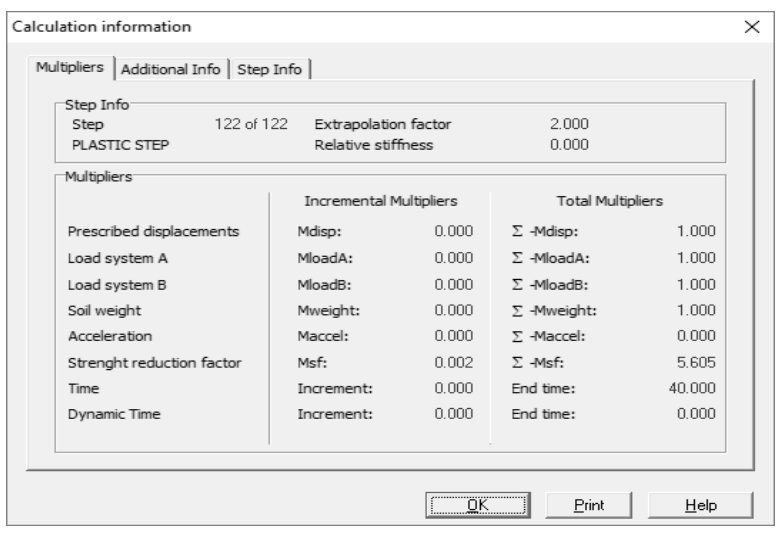

Hình 7. Hệ số ổn định của nền đất yếu được gia cố.

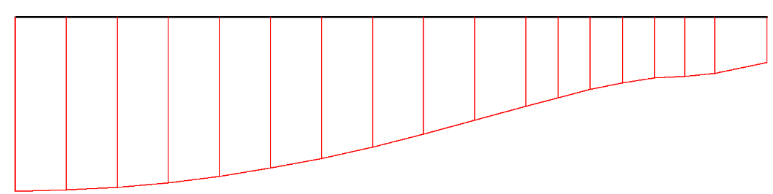

Vertical dlsplacements Uy

Exireme Us $-212611^{*} 10^{-3} \mathrm{~m}$

Hình 8. Chuyển vị đứng tại đáy bồn dầu.

\subsection{Kết quả mô phỏng và phân tích các trường hợp}

Bảng 6.

Tính toán tỉ số diện tích sử lý $\mathrm{a}_{\mathrm{s}}=\frac{\pi}{4}\left(\frac{D}{S}\right)^{2}$ 


\begin{tabular}{|l|l|l|l|l|l|}
\hline \multirow{2}{*}{$\begin{array}{l}\text { Đường kính D } \\
\text { (m) }\end{array}$} & \multicolumn{5}{|l|}{ Khoảng cách S (m) } \\
\cline { 2 - 6 } & $\mathbf{0 , 8}$ & $\mathbf{1 , 0}$ & $\mathbf{1 , 2}$ & $\mathbf{1 , 4}$ & $\mathbf{1 , 6}$ \\
\hline $\mathbf{0 , 6}$ & 0,442 & 0,283 & 0,196 & & \\
\hline $\mathbf{0 , 8}$ & & 0,503 & 0,349 & 0,256 & \\
\hline $\mathbf{1 , 0}$ & & & 0,545 & 0,401 & 0,307 \\
\hline
\end{tabular}

\section{Bảng 7.}

Chuyển vị theo phương đứng $\mathrm{L}=8 \mathrm{~m}$.

\begin{tabular}{|l|l|l|l|l|l|}
\hline \multirow{2}{*}{$\begin{array}{l}\text { Đường } \\
\text { kính D (m) }\end{array}$} & \multicolumn{5}{|l|}{ Khoảng cách $\mathbf{S}(\mathbf{m})$} \\
\cline { 2 - 6 } & $\mathbf{0 , 8}$ & $\mathbf{1 , 0}$ & $\mathbf{1 , 2}$ & $\mathbf{1 , 4}$ & $\mathbf{1 , 6}$ \\
\hline $\mathbf{0 , 6}$ & $-0,198$ & $-0,214$ & $-0,226$ & & \\
\hline $\mathbf{0 , 8}$ & & $-0,190$ & $-0,207$ & $-0,217$ & \\
\hline $\mathbf{1 , 0}$ & & & $-0,186$ & $-0,200$ & $-0,208$ \\
\hline
\end{tabular}

\section{Bảng 8.}

Hệ số an toàn $\sum M \mathrm{~s} f$ trường hợp trụ đất xi măng có chiều dài $\mathrm{L}=8 \mathrm{~m}$.

\begin{tabular}{|l|c|c|c|c|c|}
\hline \multirow{2}{*}{$\begin{array}{l}\text { Đường } \\
\text { kính D (m) }\end{array}$} & \multicolumn{5}{|c|}{ Khoảng cách S (m) } \\
\cline { 2 - 6 } & $\mathbf{0 , 8}$ & $\mathbf{1 , 0}$ & $\mathbf{1 , 2}$ & $\mathbf{1 , 4}$ & $\mathbf{1 , 6}$ \\
\hline $\mathbf{0 , 6}$ & 6,732 & 6,161 & 5,605 & & \\
\hline $\mathbf{0 , 8}$ & & 6,968 & 6,299 & 5,870 & \\
\hline $\mathbf{1 , 0}$ & & & 6,929 & 6,443 & 6,351 \\
\hline
\end{tabular}

\section{Bảng 9.}

Chuyển vị theo phương đứng $\mathrm{L}=12 \mathrm{~m}$.

\begin{tabular}{|l|c|c|c|c|c|}
\hline \multirow{2}{*}{$\begin{array}{l}\text { Đường } \\
\text { kính } \mathrm{D}(\mathbf{m})\end{array}$} & $\mathbf{0 , 8}$ & $\mathbf{1 , 0}$ & $\mathbf{1 , 2}$ & $\mathbf{1 , 4}$ & $\mathbf{1 , 6}$ \\
\cline { 2 - 6 } & $-0,107$ & $-0,123$ & $-0,132$ & & \\
\hline $\mathbf{0 , 6}$ & & $-0,102$ & $-0,117$ & $-0,126$ & \\
\hline $\mathbf{0 , 8}$ & & & $-0,098$ & $-0,112$ & $-0,119$ \\
\hline $\mathbf{1 , 0}$ & & \multicolumn{5}{|c|}{} \\
\hline
\end{tabular}

\section{Bảng 10.}

Hệ số an toàn $\sum M \mathrm{~s} f$ trường hợp trụ đất xi măng có chiều dài $\mathrm{L}=12 \mathrm{~m}$.

\begin{tabular}{|l|c|c|c|c|c|}
\hline \multirow{2}{*}{$\begin{array}{l}\text { Đường } \\
\text { kính D (m) }\end{array}$} & $\mathbf{5 , 8}$ & $\mathbf{1 , 0}$ & $\mathbf{1 , 2}$ & $\mathbf{1 , 4}$ & $\mathbf{1 , 6}$ \\
\cline { 2 - 6 } & 7,558 & 6,603 & 5,905 & & \\
\hline $\mathbf{0 , 6}$ & & 7,964 & 6,976 & 6,328 & \\
\hline $\mathbf{0 , 8}$ & & & 8,070 & 7,274 & 7,031 \\
\hline $\mathbf{1 , 0}$ & & \multicolumn{5}{|c}{} \\
\hline
\end{tabular}

Từ kết quả tính toán của Bảng 7; Bảng 8; Bảng 9; Bảng 10 tương ứng với các đồ thị sau đây:

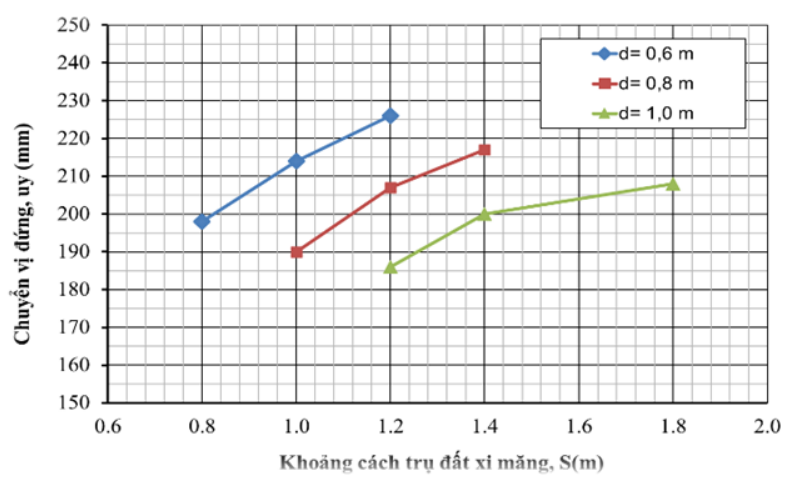

Hình 9. Chuyển vị đứng của nền đất yếu được gia cố, $\mathrm{L}=8 \mathrm{~m}$.

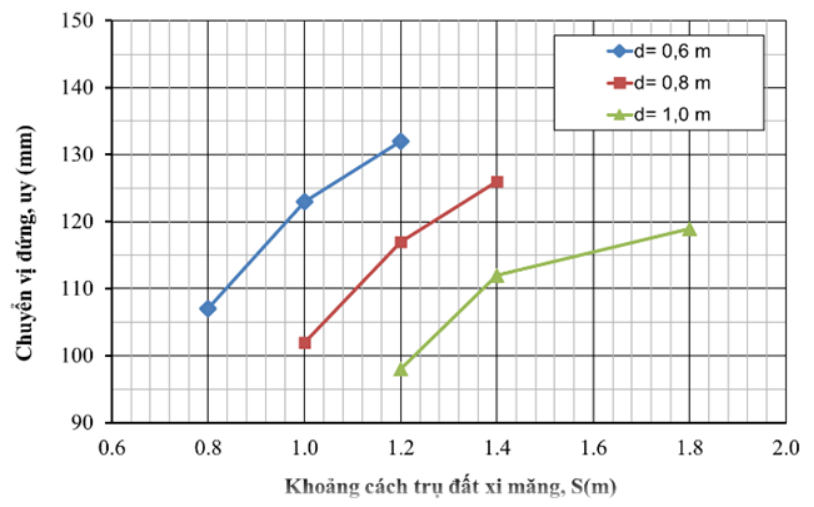

Hình 10. Chuyển vị đứng của nền đất yếu được gia cố, $\mathrm{L}=12 \mathrm{~m}$.

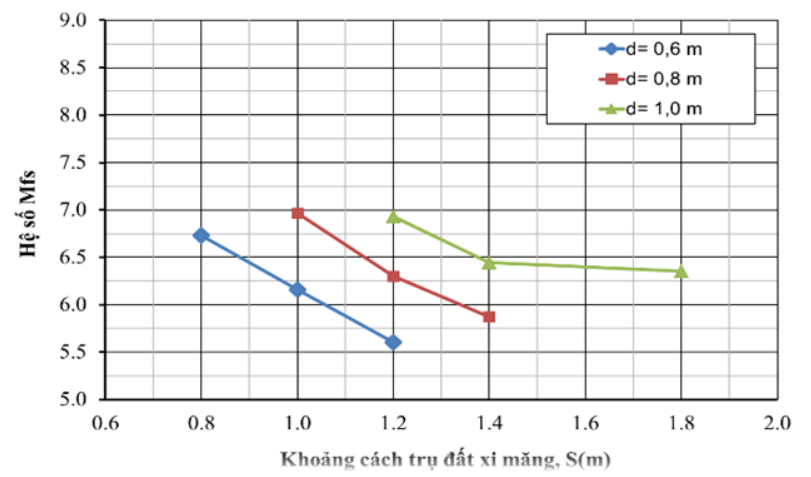

Hình 11. Hệ số ổn định của nền đất yếu được gia cố , $\mathrm{L}=8 \mathrm{~m}$. 


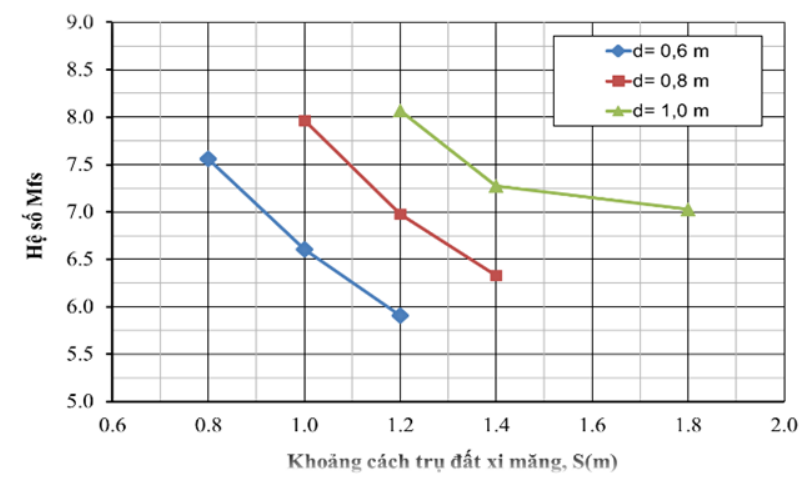

Hình 12. Hệ số ổn định của nền đất yếu được gia cố, $\mathrm{L}=12 \mathrm{~m}$.

Bố trí trụ đất xi măng được xác định bởi tỉ số diện tích cải tạo thấp được tính toán trong Bảng 6 . Theo Bảng 6 , tỉ số diện tích cải tạo thấp $\left(\mathrm{a}_{\mathrm{s}}=0,196\right)$ tương ứng với trường hợp: đường kính trụ đất xi măng là $0,6 \mathrm{~m}$; khoảng cách trụ 1,2 m.

Tính toán độ lún của nền bể chứa xăng dầu sau khi cải tạo bằng trụ đất xi măng bằng phần mềm Plaxis. Tổng độ lún gồm độ lún của nền đất đã được cải tạo và nền đất phía dưới vùng cải tạo của trụ đất xi măng có đường kính $0,6 \mathrm{~m}$; khoảng cách $1,2 \mathrm{~m}$, chiều dài $8 \mathrm{~m}$ với độ lún bằng $0,226 \mathrm{~m}$ và hệ số ổn định 5,605 . Độ lún này nhỏ hơn độ lún giới hạn cho phép.

Căn cứ vào tỉ số diện tích cải tạo thấp $\left(\mathrm{a}_{\mathrm{s}}=0,196\right)$ và độ lún nhỏ hơn giới hạn cho phép ( < 0,4 m - TCVN 10304:2014), thiết kế hợp lý của trụ đất xi măng trong trường hợp này là trường hợp 3 - A (D = $0,6 \mathrm{~m} ; \mathrm{S}=1,2 \mathrm{~m} ; \mathrm{L}=8 \mathrm{~m}$ ).

\section{Kết luận}

Kết quả tính toán có thiết kế hợp lý là hệ trụ đất xi măng đường kính $0,6 \mathrm{~m}$, chiều dài $8 \mathrm{~m}$ và khoảng cách các trụ là $1,2 \mathrm{~m}$. Với đặc điểm công trình bể chứa là có tải trọng phân bố đều khắp trên toàn diện tích phù hợp với giải pháp trụ đất xi măng cho công trình móng bản diện truyền tải rộng, tải trọng của công trình không lớn, chiều dày lớp đất yếu nhỏ hơn $20 \mathrm{~m}$. Với tải trọng công trình từ 100 đến $200 \mathrm{kN} / \mathrm{m}^{2}$ thì phù hợp với địa chất ở tỉnh Tiền Giang có chiều dày lớp đất yếu nhỏ hơn 12 m.

Trụ đất xi măng được ứng dụng hiệu quản để xử lý nền đất yếu cho công trình bể chứa xăng dầu củng như các công trình có thời gian thi công ngắn, độ lún nhỏ, đất cố kết nhanh. Kết quả tính toán giúp lập phương án thiết kế phù hợp. Với những bài toán tính ổn định công trình củng như tính ổn định nền đắp không chỉ phải đánh giá trong giai đoạn dài hạn khi công trình hoàn thành mà còn phải đánh giá trong các bước thi công.

\section{Tài liệu tham khảo}

[1]. Bộ Khoa học và Công nghệ, Gia cố nền đất yếu - Phương pháp trụ đất xi măng, TCVN9403-2012, 2012, Hà Nội.

[2]. Bruce, D. A. An Introduction to the Deep Soil Mixing Methods as used in Geotechnical Applications, FHWA-RD-99-138, Federal Highway Admisnistration, McClean, VA, 2000.

[3]. Engan Kaihatsu Gijutsu Kenkyū Sentā (Japan), Ed., The deep mixing method: principle, design, and construction. Lisse ; Exton, PA: A.A. Balkema Publishers, 2002.

[4]. V. N. Đậu, Giải pháp xử lý đất yếu bằng đất trộn xi măng, Trường Đại học Bách Khoa, ĐHQG-HCM, Tạp chí Phát triển KH\&CN, tập 11, số 11-2008, 2008, trang 57-63.

[5]. Công ty trách nhiệm hữu hạn một thành viên Thành Phú TG, Hồ sơ báo cáo địa chất công trình tại tp Mỹ Tho - tỉnh Tiền Giang, 2020.

[6]. Lareal, N. T. Long, Le. B. Lương, N.Q. Chiêu and V. D. Lục , Công trình trên đất yếu trong điều kiện Việt Nam, Trường Đại học Kỹ thuật TP Hồ Chí Minh, 1994.

[7]. N. V. Trung , V. M. Tuấn, Cọc xi măng đất - Phương pháp gia cố nền đất yếu, Nhà xuất bản Xây dựng, 2014.

[8]. T. N. Tiến, Kỹ thuật đường ống và bể chứa, NXB Đà Nẵng, 2008. 